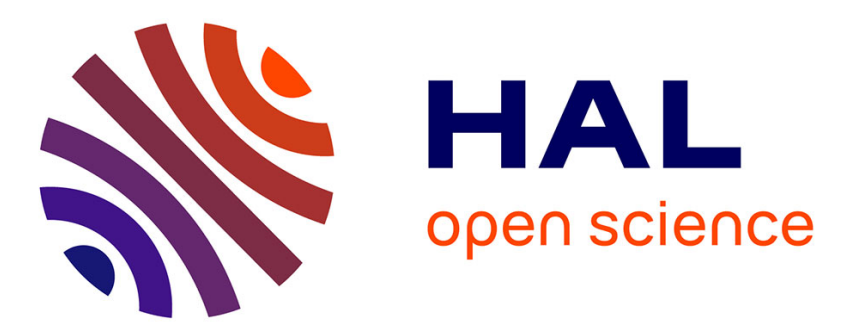

\title{
Gear ratio optimization of a full magnetic indirect drive chain for wind turbine applications
}

Melaine Desvaux, Bernard Multon, Hamid Ben Ahmed, Stéphane Sire, Aurélie Fasquelle, Daniel Laloy

\section{- To cite this version:}

Melaine Desvaux, Bernard Multon, Hamid Ben Ahmed, Stéphane Sire, Aurélie Fasquelle, et al.. Gear ratio optimization of a full magnetic indirect drive chain for wind turbine applications. Twelfth International Conference on Ecological Vehicles and Renewable Energies (EVER), 2017, Apr 2017, Monte Carlo, Monaco, France. pp.1 - 9, 10.1109/EVER.2017.7935894 . hal-01598095

\section{HAL Id: hal-01598095 \\ https://hal.science/hal-01598095}

Submitted on 29 Sep 2017

HAL is a multi-disciplinary open access archive for the deposit and dissemination of scientific research documents, whether they are published or not. The documents may come from teaching and research institutions in France or abroad, or from public or private research centers.
L'archive ouverte pluridisciplinaire HAL, est destinée au dépôt et à la diffusion de documents scientifiques de niveau recherche, publiés ou non, émanant des établissements d'enseignement et de recherche français ou étrangers, des laboratoires publics ou privés. 


\section{Gear Ratio Optimization of a Full Magnetic Indirect Drive Chain for Wind Turbine Applications}

\author{
Melaine Desvaux, \\ Bernard Multon and Hamid Ben Ahmed \\ SATIE, ENS Rennes \\ Univ. Bretagne Loire, CNRS \\ 35170 Bruz, France \\ Email: melaine.desvaux@ens-rennes.fr
}

\author{
Stéphane Sire \\ Univ. Bretagne Occidentale \\ FRE CNRS 3744, IRDL \\ 29238 Brest, France \\ Email: stephane.sire@univ-brest.fr
}

\author{
Aurélie Fasquelle \\ Daniel Laloy \\ Jeumont Electric \\ 59572 Jeumont, France \\ Email:
}

aurelie.fasquelle@jeumontelectric.com

\begin{abstract}
This article deals with the optimization of a full magnetic indirect drive (FMID) with magnetic gears which uses an analytical model based on subdomain resolution of Laplace's and Poisson's equations of the magnetic gear. A bi-objective analytical optimization is performed with a PSO algorithm with a minimization of the mass of the magnetic parts and a maximization of the gear ratio. This intermediate optimization is a step to optimize a $6 \mathrm{MW}$ FMID for a offshore wind turbine with one or two magnetic gears stages. It also compares FMID magnetic parts masses with a direct drive conversion chain with the same generator topology (hybrid excitation synchronous generator).
\end{abstract}

Keywords- magnetic gear; conversion chain; full magnetic indirect drive (FMID); optimization; analytical model; wind turbine.

\section{NOMENCLATURE}

$A^{(k)}$ : Magnetic vector potential of the region $\mathrm{k}$ $B_{r}^{(k)}$ : Radial flux density in the region $\mathrm{k}[\mathrm{T}]$ $B_{\alpha}^{(k)}$ : Tangential flux density in the region $\mathrm{k}[\mathrm{T}]$ $C_{f}$ : Cogging torque factor

$D_{M G}$ : Magnetic diameter of the magnetic gear [m] $D_{S G}$ : Magnetic diameter of the synchronous generator [m]

FMID: Full magnetic indirect drive

$G$ : Gear ratio

$G_{i}:$ Gear ratio of the stage $i$ of the FMID

$G_{F M I D-i s}:$ Global gear ratio of the FMID with $i$ stages

$k$ : Index of the magnetic gear region

$L_{M G}$ : Magnetic length of the magnetic gear [m]

$L_{S G}$ : Magnetic length of the synchronous generator [m]

$M_{F M I D-i S}$ : Mass of the FMID with $i$ stages [kg]
$M_{S G}:$ Mass of the synchronous generator [kg]

$N$ : Number of harmonics taken into account in the other regions (region $\mathrm{X}, \mathrm{I}, \mathrm{II}, \mathrm{IV}, \mathrm{V}$ and VI)

$N_{Q}$ : Number of harmonics taken into account in the air space between pole pieces (region III)

$p_{\text {int }}$ : Number of internal ring pole pairs

$p_{\text {ext }}$ : Number of external ring pole pairs

$Q$ : Number of ferromagnetic pole pieces

$r$ : Radius cylindrical coordinate [m]

$R_{M}^{(k)}$ : External radius of the region $\mathrm{k}[\mathrm{m}]$

$R_{m}^{(k)}$ : Internal radius of the region $\mathrm{k}[\mathrm{m}]$

$T^{(k)}$ : Torque computed in the region $\mathrm{k}[\mathrm{Nm}]$

$T_{S G}$ : Torque of the synchronous generator [Nm]

$T_{\text {rated }}$ : Rated torque of the wind turbine [Nm]

$\alpha$ : Angular cylindrical coordinate [rad]

$\sigma_{t}$ : Tangential stress of the generator $\left[\mathrm{N} / \mathrm{m}^{2}\right]$

$\xi$ : Filling factor of the synchronous generator $(0<\xi<1)$

$\mu_{(k)}$ : Relative permeability of region $\mathrm{k}$

$\omega_{\text {int } / 0}$ : Rotational speed of the internal ring $[\mathrm{rad} / \mathrm{s}]$

$\omega_{\text {ext } / 0}$ : Rotational speed of the external ring [rad/s]

$\omega_{Q / 0}$ : Rotational speed of the pole piece $\mathrm{ring}[\mathrm{rad} / \mathrm{s}]$

\section{INTRODUCTION}

For multi-megawatt wind turbines, mechanical gearboxes are frequently used in indirect drive; this design allows to obtain a lower cost of investment and a lower weight compared to direct drive designs [1]. However, failures of mechanical gearboxes, induced production interruptions and operating costs are higher than in direct drive design [2]-[3].

In this paper, we investigate an intermediate solution i.e a combination of a hybrid excitation synchronous generator with one or two magnetic gears stages. We call it full 
magnetic indirect drive (FMID) [4]-[5]. The most attractive magnetic gears topology has been proposed by Martin [6] and was the subject of different studies proposed by Atallah [7]-[8] and others [9]-[10]. This magnetic gear can be integrated in a one or two stages of FMID like Fig.1. This architecture includes a rapid rotor with permanent magnets (internal permanent magnets ring), a slow rotor with ferromagnetic pole pieces and a fixed permanent magnets ring (external permanent magnets ring) for each stage of magnetic gear, as shown in the Fig.2. A hybrid excitation synchronous generator developed by Jeumont Electric [11][12] is integrated in the conversion chain after the last stage of gear (Fig.1). This topology potentially offers high performance and must be strongly optimized to give a hope of competitiveness compared to indirect drive with mechanical gears and even for high torque applications (offshore wind turbine for instance) [13].
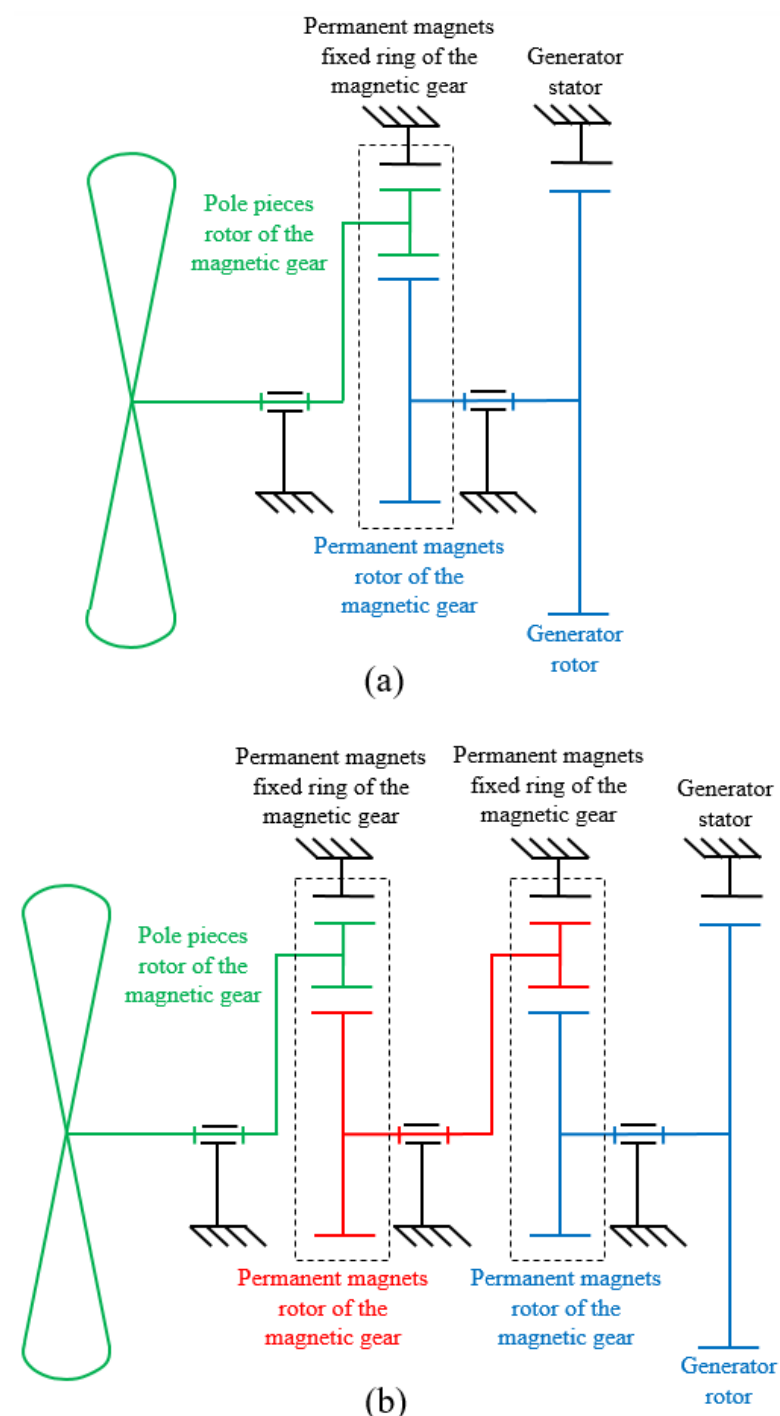

(b)

Fig. 1: Functional scheme of magnetic Indirect Drive (MID) conversion chain with (a) one stage of magnetic gear, (b) two magnetic gear stages.
Some magnetic gear drive optimization work has already been done on the magnetic parts masses of the magnetic gear [14]-[15]. However, to our knowledge, no work has been conducted on the optimization of drive chain with two magnetic gears stages, including the generator. The major contribution of this work is the implementation of a second objective function (the gear ratio) which permit to optimize a two stages FMID (Fig. 1b) with analytical model and compared with a single stage FMID (Fig. 1a) optimized solution and a direct drive hybrid excitation synchronous generator design.

\section{DESCRIPTION OF THE MAGNETIC GEAR}

The one stage magnetic gear topology [6] is composed of three rings :

- An internal ring with $p_{\text {int }}$ pole pairs of permanent magnets with a ferromagnetic yoke,

- An external ring with $p_{\text {ext }}$ pole pairs of permanent magnets with a ferromagnetic yoke,

- A ring with Q ferromagnetic poles between both permanent magnets ring, (an example is given in Fig. 2 with low pole numbers, to improve readability: $p_{\text {int }}=2, p_{\text {ext }}=7$ and $Q=9$ ).

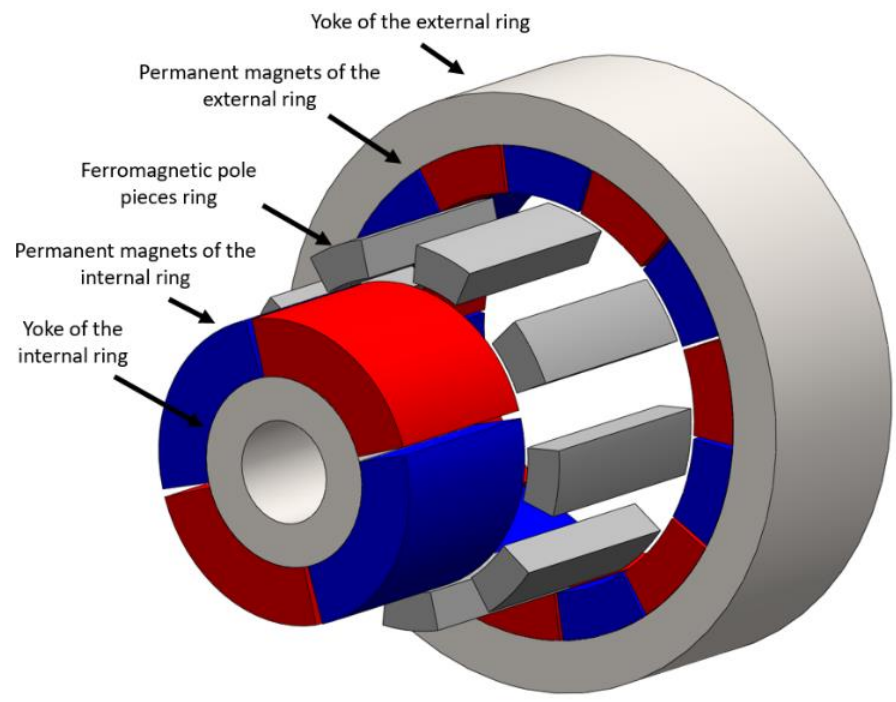

FigG.2. Magnetic gear architecture proposed by [6] in an exploded drawing with low pole numbers (in this example: $p_{\text {int }}=2, p_{\text {ext }}=7$ and $Q=9$ ).

Each permanent magnets ring generates in air gaps a wave of magnetomotive force. Ring with ferromagnetic pole pieces aims to modulate the magnetic field in the two air gaps to obtain common harmonics. The result is a magnetic torque with an average different from zero and a transmission of power with a synchronism between fundamental magnetic field frequencies in both air gaps. 
To achieve this power transmission, the pole numbers of the three rings must respect equation (1). Then, it is possible to define the ratio $\lambda$ (2) and the Willis relation for a magnetic gear (3) like a planetary gear [16] where $\omega_{\text {int } / 0}, \omega_{\text {ext } / 0}$ and $\omega_{Q / 0}$ are the speed rotation of the internal ring, the external ring and the pole pieces ring respectively. Depending on the fixed ring, the gear ratio $G$ is given by (4). In this article, only the case where the external permanent magnet ring is fixed is studied because this case maximizes the gear ratio and then minimizes the output torque.

$$
\begin{gathered}
p_{\text {int }}+p_{\text {ext }}=Q \\
\lambda=\frac{\omega_{\text {int } / 0}-\omega_{Q / 0}}{\omega_{\text {ext } / 0}-\omega_{Q / 0}}=-\frac{p_{\text {ext }}}{p_{\text {int }}} \\
\omega_{\text {int } / 0}-\lambda \cdot \omega_{\text {ext } / 0}+(\lambda-1) \cdot \omega_{Q / 0}=0 \\
\left\{\begin{array}{l}
\omega_{\text {int } / 0}=0 \rightarrow G=\frac{\omega_{\text {ext } / 0}}{\omega_{Q / 0}}=\frac{(\lambda-1)}{\lambda} \\
\omega_{Q / 0}=0 \rightarrow G=\frac{\omega_{\text {int } / 0}}{\omega_{\text {ext } / 0}}=\lambda \\
\omega_{\text {ext } / 0}=0 \rightarrow G=\frac{\omega_{\text {int } / 0}}{\omega_{Q / 0}}=-(\lambda-1)
\end{array}\right.
\end{gathered}
$$

To minimize the torque ripple, a cogging torque factor $C_{f}$ has been defined by [8] which represents the number of symmetries of the system (5). It is then possible to impose the relation $C_{f}=1$ to ensure the minimum of torque ripple where $N_{c}\left(2 . p_{\text {int }}, Q\right)$ is the smallest common multiple between 2. $p_{\text {int }}$ and $Q$. This relation also minimizes the number of magnetic symmetries.

$$
C_{f}=\frac{2 \cdot p_{\text {int }} \cdot Q}{N_{c}\left(2 \cdot p_{\text {int }}, Q\right)}
$$

\section{MAGNETOSTATIC ANALYTICAL MODEL OF THE MAGNETIC GEAR}

To evaluate the magnetic torque, it is first necessary to determine the magnetic field distribution in the different regions of the system, presented in Fig. 3. To compute it, a 2-D magneto static model, developed by [17] without any magnetic field computation in yokes and by [18] with magnetic field computation in yokes, is used with radial magnetization of magnets, constant remanence of the magnets and a constant relative permeability for all materials. This analytical model requires to solve Poisson's and Laplace's equation (6) in the k region of the system [19] (yokes region, permanent magnet region, air gap region and each air space between pole pieces) where
$A^{(k)}$ and $M^{(k)}$ are the magnetic vector potential and the radial magnetization distribution respectively, $r$ and $\alpha$ are the cylindrical coordinates.

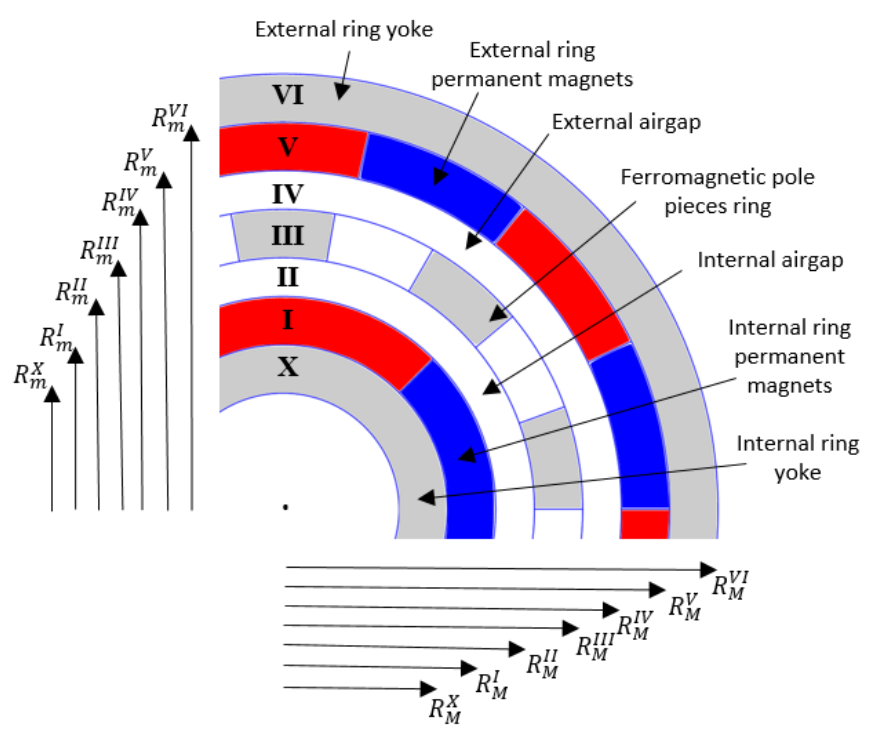

Fig.3. Magnetic gear parametrization of the different regions (in this example: $p_{\text {int }}=2, p_{\text {ext }}=7$ and $Q=9$ ).

$$
\Delta A^{(k)}=\left\{\begin{array}{c}
-\frac{1}{r} \frac{\partial M^{(k)}}{\partial \alpha} \\
0
\end{array}\right.
$$

For Poisson's and Laplace's equations, a general solution (7) can be found in the $k$ region of the system by using the method of the separation of variable [20] where $X_{0}^{(k)}, Y_{0}^{(k)}, C_{n}^{(k)}, D_{n}^{(k)}, K_{n}^{(k)}, E_{n}^{(k)}$ are constants of integration, $a_{n}^{(k)}$ and $b_{n}^{(k)}$ are the general solution of the Poisson's equation and $R_{M}^{(k)}=R_{m}^{(k+1)}$ in agreement with Fig. 3. For region III, the expression is different due to boundary conditions (based on an infinite relative permeability of pole pieces). The analytical solution is then (8), where $\beta$ is the slot opening angle and $\alpha_{q}$ is described in (9) with $1<q<Q$.

$$
\begin{aligned}
& A^{(k)}\left(r, \alpha, \theta^{(k)}\right)=X_{0}^{(k)}+Y_{0}^{(k)} \ln \left(\frac{r}{R_{M}^{(k)}}\right) \\
& +\sum_{n \geq 1}^{N}\left(C_{n}^{(k)}\left(\frac{r}{R_{M}^{(k)}}\right)^{n}+D_{n}^{(k)}\left(\frac{r}{R_{m}^{(k)}}\right)^{-n}+a_{n}^{(k)}\right) \cos (n . \alpha) \\
& +\sum_{n \geq 1}^{N}\left(K_{n}^{(k)}\left(\frac{r}{R_{M}^{(k)}}\right)^{n}+E_{n}^{(k)}\left(\frac{r}{R_{m}^{(k)}}\right)^{-n}+b_{n}^{(k)}\right) \sin (n . \alpha)
\end{aligned}
$$




$$
\begin{gathered}
A^{(I I I, q)}(r, \alpha)=X_{0}^{(I I I, q)}+Y_{0}^{(I I I, q)} \ln \left(\frac{r}{R_{M}^{(I I I, q)}}\right) \\
+\sum_{m \geq 1}^{N_{Q}}\left(C_{m}^{(I I I, q)}\left(\frac{r}{R_{M}^{(I I I, q)}}\right)^{m \frac{\pi}{\beta}}+D_{m}^{(I I I, q)}\left(\frac{r}{R_{m}^{(I I I, q)}}\right)^{-m \frac{\pi}{\beta}}\right) \\
. \cos \left(m \frac{\pi}{\beta}\left(\alpha-\alpha_{q}\right)\right) \\
\alpha_{q}=-\frac{\beta}{2}+\frac{2 . q \cdot \pi}{Q}
\end{gathered}
$$

For the various problem boundaries, conditions should be given by the equations presented in (10). From these boundary conditions, it is possible to obtain a matrix system of equations $\mathrm{Z}$ where the constants of integration presented in (7)-(8) are the unknowns of the problem. The dimension of the matrix $\mathrm{Z}$ presented in (11) is dependent of $N_{Q}$ the number of harmonics taken into account in the air space between pole pieces (region III), $Q$ the number of pole pieces and $N$ the number of harmonics taken into account in the other regions (region X, I, II, IV, V and VI) [18]. This matrix must be inverted to determine the magnetic field distribution.

$$
\left\{\begin{array}{c}
r=R_{m}^{(X)}, R_{M}^{(V I)} \rightarrow A^{(k)}=0 \\
\left\{\begin{array}{c}
r=R_{M}^{(I I)}, R_{m}^{(I V)} \\
\forall \alpha \in\left[\alpha_{q}+\beta, \alpha_{q+1}\right]
\end{array} \rightarrow \frac{\partial A^{(k)}}{\partial r}=0\right. \\
\left\{\begin{array}{c}
\alpha=\alpha_{q}, \alpha_{q}+\beta \\
\forall r \in\left[R_{m}^{(I I I)}, R_{M}^{(I I I)}\right]
\end{array} \rightarrow \frac{\partial A^{(I I I, q)}}{\partial \alpha}=0\right. \\
k=\left.X \ldots V \rightarrow \frac{\partial A^{(k)}}{. \partial r}\right|_{r=R_{M}^{(k)}}=\left.\frac{\partial A^{(k+1)}}{\partial r}\right|_{r=R_{m}^{(k+1)}} \\
k=\left.I \ldots V I \rightarrow A^{(k)}\right|_{r=R_{m}^{(k)}}=\left.A^{(k-1)}\right|_{r=R_{M}^{(k-1)}} \\
\operatorname{Dim}(Z)=\left(20 N+\left(2 N_{Q}+2\right) Q\right)^{2}
\end{array}\right.
$$

When the magnetic potential vector is determined in several subdomains of the magnetic gear, it is possible to draw the magnetic flux line distribution as shown in Fig.4. The magnetic torque can be computed with (12) where the radius $R_{m}^{(k)}<R<R_{M}^{(k)}, B_{r}^{(k)}$ is the radial flux, $B_{\alpha}^{(k)}$ is the tangential flux (13). Comparison can then be drawn between the magnetic torque of the internal and external rings obtained with the analytical model and finite element model with a rotation of the internal ring while keeping the pole-piece ring and the external ring fixed (Fig.5).

$$
\begin{array}{r}
T^{(k)}=\frac{L_{z} \cdot R^{2}}{\mu_{0}} \sum_{n \geq 1} \int_{0}^{2 \pi} B_{r}^{(k)}(R, \alpha) \cdot B_{\alpha}^{(k)}(R, \alpha) d \alpha \\
\left\{\begin{array}{l}
B_{r}^{(k)}=\frac{1}{r} \frac{\partial A^{(k)}}{\partial \alpha} \\
B_{\alpha}^{(k)}=-\frac{\partial A^{(k)}}{\partial r}
\end{array}\right.
\end{array}
$$

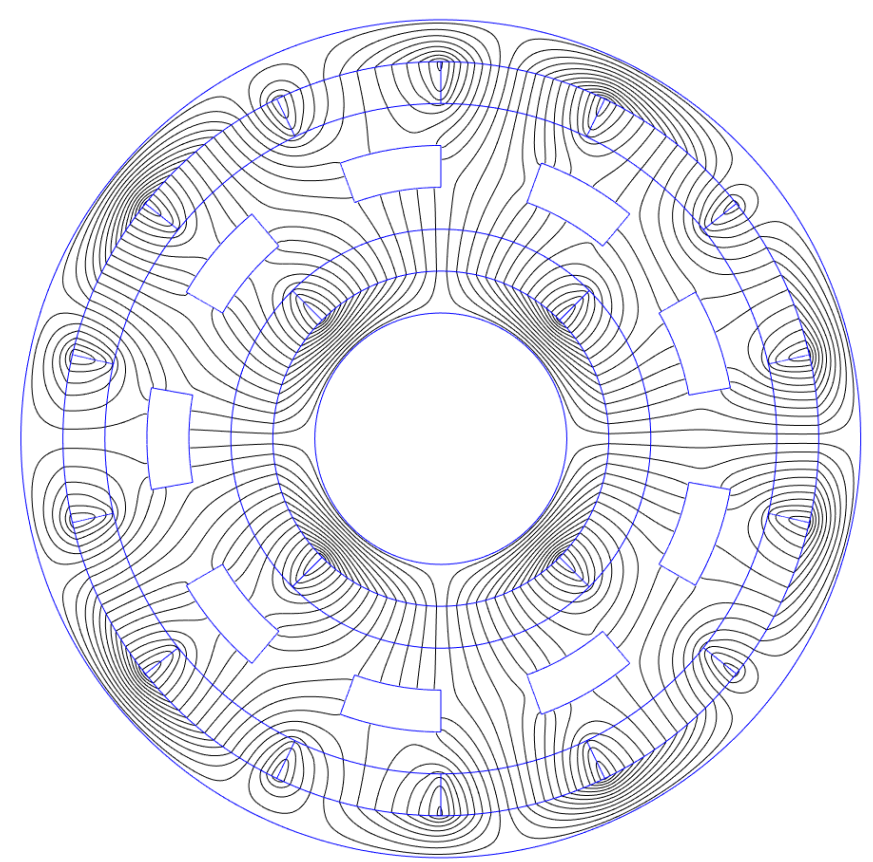

Fig. 4: 2-D representation of the magnetic flux line distribution in a magnetic gear obtained with the magnetostatic analytical model [18]. In this example: $p_{\text {int }}=2, p_{\text {ext }}=7$ and $Q=9$ (flux line distribution is not represented in pole pieces because the analytical model does not permit to compute the magnetic vector potential in these regions).

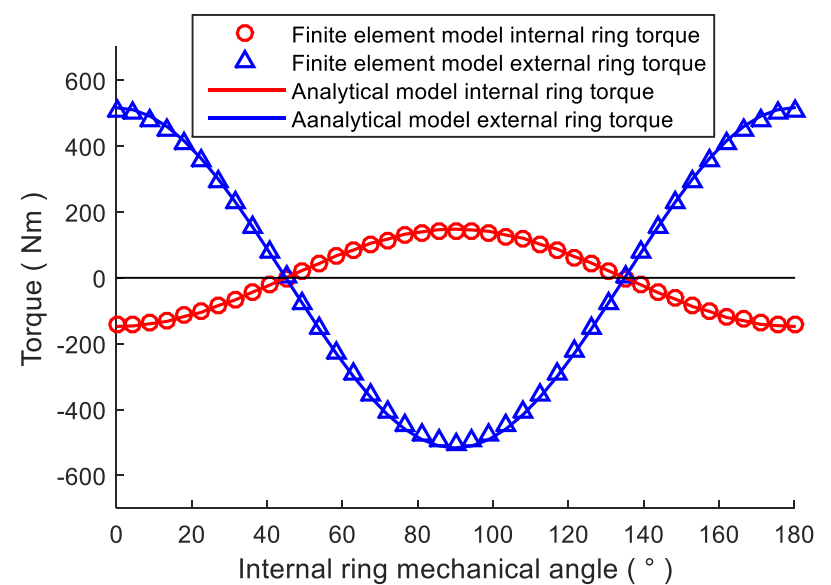

Fig.5: Magnetic torque evolution using an analytical model and a finite element model with a rotation of the internal ring while keeping the pole-piece ring and the external ring fixed for a magnetic gear with $p_{\text {int }}=2, p_{\text {ext }}=7$ and $Q=9$. 
For high power application like wind turbines (on the order of the MW), magnetic gears have high pole number which increases the dimension of the matrix Z (11) and then the computation time. To reduce the computation time, [18], an harmonics selection method is proposed. It permits to build the matrix system of the analytical model $Z$ only with harmonics which generate magnetic fields. The number of harmonics taken into account is $N_{Q}=5$ and $N=3$. $p_{\text {ext }}$. With these values, the computation time of the torque is equal to $0.4 \mathrm{sec}$ with an error lower than $1 \%$ for high pole number magnetic gears and it can be done for only one position.

\section{PRELIMINARY BI-OBJECTIVE OPTIMIZATION OF MAIN GEOMETRIC PARAMETERS OF MAGNETIC GEAR}

\section{A. Objective functions}

The objective functions of the preliminary bi-objective optimization (14) are to minimize the magnetic gear masses with the objective function $C_{1}$ and to minimize the opposite of the gear ratio with the objective function $C_{2}$ (which correspond to maximize the gear ratio). The different parts which are considered for the calculation of the mass are the yokes of the internal and external rings, permanent magnets of the internal and external rings and the pole pieces. Material properties of this different parts are defined in Table 2 (pole pieces and yokes are in the same ferromagnetic steel).

$$
\left\{\begin{array}{c}
C_{1}=\rho_{P M} \cdot V_{P M}+\rho_{s} \cdot V_{S} \\
C_{2}=-\frac{n_{S}}{p_{\text {int }}}
\end{array}\right.
$$

TABLE 2: MATERIAL PHYSICAL PROPERTIES

\begin{tabular}{|c|c|c|}
\hline Symbol & Quantity & Value \\
\hline $\mathrm{N} 38 \mathrm{SH}$ & Permanent magnet designation & - \\
\hline$B_{r}$ & Remanence of the magnets & $1.26 \mathrm{~T}$ \\
\hline$\rho_{P M}$ & Density of permanent magnets & $7,500 \mathrm{~kg} / \mathrm{m}^{3}$ \\
\hline $\mathrm{M} 400-65$ & Ferromagnetic steel designation & - \\
\hline$\rho_{S}$ & Density of the ferromagnetic steel & $7,800 \mathrm{~kg} / \mathrm{m}^{3}$ \\
\hline
\end{tabular}

\section{B. Geometric parameters}

The optimization is composed of seven parameters: yoke thicknesses, permanent magnet thicknesses, ferromagnetic pole thicknesses and pole pair number of the permanent magnet rings. For the optimization step, it is necessary to define a value range for all geometric parameters (see Table 3 below).

TABLE 3: VALUE RANGE OF THE GEOMETRIC PARAMETERS

\begin{tabular}{|c|c|c|c|}
\hline Symbol & Quantity & $\begin{array}{c}\text { Minimum } \\
\text { value }\end{array}$ & $\begin{array}{c}\text { Maximum } \\
\text { value }\end{array}$ \\
\hline$p_{\text {int }}$ & $\begin{array}{c}\text { Number of internal ring pole } \\
\text { pairs }\end{array}$ & 5 & 100 \\
\hline$p_{\text {ext }}$ & $\begin{array}{c}\text { Number of external ring pole } \\
\text { pairs }\end{array}$ & 50 & 200 \\
\hline$e_{\text {yoke int }}$ & $\begin{array}{c}\text { Radial thickness of the } \\
\text { internal ring yoke }\end{array}$ & $20 \mathrm{~mm}$ & $400 \mathrm{~mm}$ \\
\hline$e_{\text {yoke ext }}$ & $\begin{array}{c}\text { Radial thickness of the } \\
\text { external ring yoke }\end{array}$ & $20 \mathrm{~mm}$ & $400 \mathrm{~mm}$ \\
\hline$e_{P M \text { int }}$ & $\begin{array}{c}\text { Radial thickness of the } \\
\text { internal ring permanent } \\
\text { magnets }\end{array}$ & $20 \mathrm{~mm}$ & $200 \mathrm{~mm}$ \\
\hline$e_{P M \text { ext }}$ & $\begin{array}{c}\text { Radial thickness of the } \\
\text { external ring permanent } \\
\text { magnets }\end{array}$ & $20 \mathrm{~mm}$ & $200 \mathrm{~mm}$ \\
\hline$e_{S}$ & $\begin{array}{c}\text { Radial thickness of } \\
\text { ferromagnetic pole pieces }\end{array}$ & $20 \mathrm{~mm}$ & $200 \mathrm{~mm}$ \\
\hline
\end{tabular}

\section{Constraints}

The magnetic gear is optimized to be integrated in a wind turbine conversion chain $6 \mathrm{MW}, 12.5 \mathrm{rpm}$ with one or two magnetic gear stages. Some magnetic gear dimensions were imposed by the wind turbine, whereas other dimensions, like the air gap length, were imposed by assembly feasibility constraints. All fixed magnetic gear dimensions are listed in Table 4.

TABLE 4: DATA AND CONSTRAINTS ASSOCIATED WITH THE WIND TURBINE CONVERSION CHAIN

\begin{tabular}{|c|c|c|}
\hline Symbol & Quantity & Value \\
\hline$P_{\text {rated }}$ & Rated power & $6 \mathrm{MW}$ \\
\hline$N_{\text {rated }}$ & Rated speed of the turbine & $12.5 \mathrm{rpm}$ \\
\hline$T_{\text {rated }}$ & Rated torque & $4.6 \mathrm{MNm}$ \\
\hline$T_{G}$ & Maximum magnetic gear torque & $5.1 \mathrm{MNm}$ \\
\hline$D_{G M}$ & Magnetic parts external diameter & $5.5 \mathrm{~m}$ \\
\hline$\delta_{\text {int }}$ & Length of radial internal airgap & $5 \mathrm{~mm}$ \\
\hline$\delta_{\text {ext }}$ & Length of radial external airgap & $5 \mathrm{~mm}$ \\
\hline
\end{tabular}

Considering that the analytical model contains linear material properties, it is necessary to impose a maximal tolerated induction in yokes. Then, a maximal induction of $1.5 \mathrm{~T}$ is fixed in yokes.

\section{Procedure of optimization}

Fig. 6 describes the bi-objective optimization procedure. To begin, an initial set of parameters is computed, then the magnetostatic 2D analytical computation is conducted. This analysis provides the magnetic torque per unit length. Next, the magnetic part length $L_{z}$ is assumed to transmit a torque of $1 \mathrm{MNm}$. This value has been chosen to normalize the problem in order to achieve the two stages conversion chain problem. The magnetic part masses of the magnetic gear is then determined in $\mathrm{kg} / \mathrm{MNm}$. The objective functions and 
inductions constraints are evaluated for this pair of parameters.

To complete this optimization procedure, a Particle Swarm Optimization (PSO) algorithm was used, as described in [21] and [22]. PSO is a stochastic search and optimization algorithm, in which the trajectory of each particle (parameter) is adjusted towards its own best position, and the overall best position is calculated using neighbors as well as the whole swarm [23]. This algorithm then chooses different parameter sets in order to minimize the objective function until the maximum iteration number has been reached. The optimal solution minimizes the objective functions while respecting the induction constraints. This optimization is performed with 400 particles and 200 iterations.

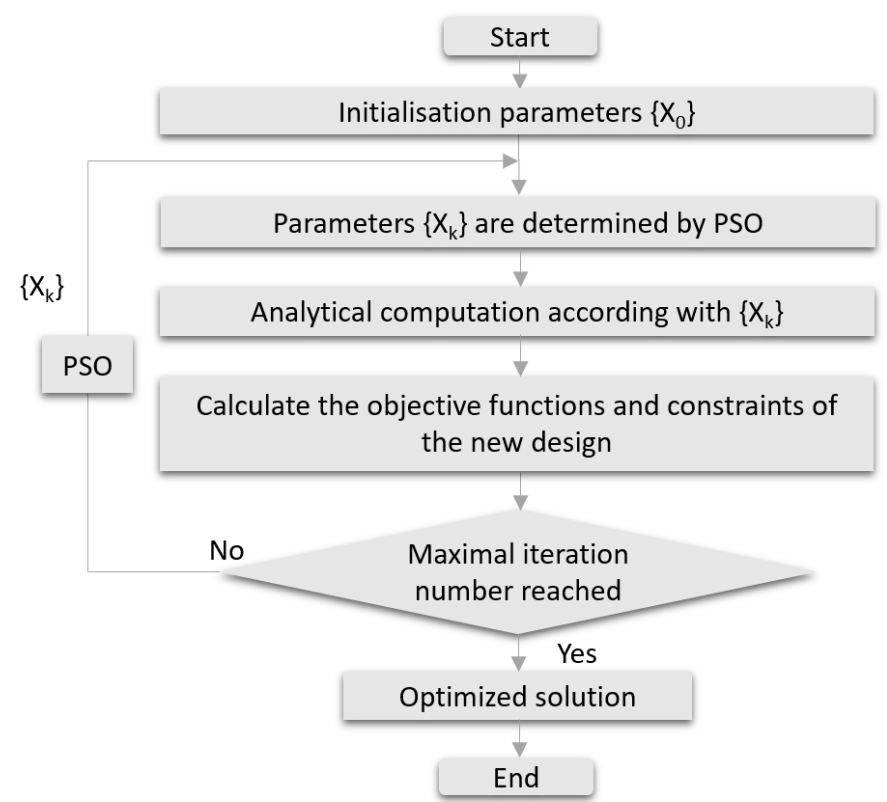

Fig. 6 Procedure of the optimization algorithm with the PSO (Particle Swarm Optimization) method.

\section{E. Result of the preliminary optimization}

Fig. 7 shows the front of Pareto of the PSO biobjective optimization with the objective function (14). From this optimization, it is possible to fit a curve passing through the front of Pareto which is a three-order function Pareto $(G)$ in Tons $/ \mathrm{MNm}(15)$ visible Fig. 7 with $\mathrm{a}=-0.41$, $\mathrm{b}=20.9, \mathrm{c}=247$ and $\mathrm{d}=1790$ with $95 \%$ confidence bounds. This result will be used to optimize the gear ratio of a 6 MW, $12.5 \mathrm{rpm}$ conversion chain with one or two magnetic gear stages and a hybrid excitation synchronous generator (Jeumont Electric). Considering $G_{1}$ the gear ratio of the first stage of magnetic gear and $G_{2}$ the gear ratio of the second stage of magnetic gear, the global gear ratio of a
FMID with one stage of magnetic gear $G_{F M I D-1 S}$ is given by (16) and the global gear ratio of a FMID with two magnetic gear stages $G_{F M I D-2 S}$ is given by (17). A comparison can then be done with a direct drive design which contains the same topology of hybrid excitation synchronous generator.

$$
\begin{gathered}
\operatorname{Pareto}(G)=\text { a. } G^{3}+\text { b. } G^{2}+\text { c. } G+\mathrm{d} \\
G_{F M I D-1 S}=G_{1} \\
G_{F M I D-2 S}=G_{1} \cdot G_{2}
\end{gathered}
$$

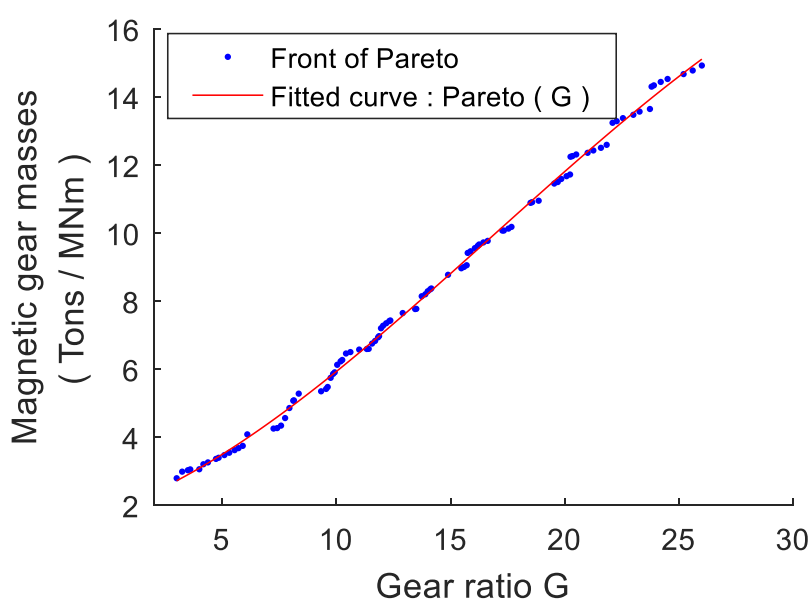

Fig. 7 Front of Pareto of the PSO bi-objective optimization with its order function three fitted curve for only one stage of magnetic gear and a constant external diameter.

\section{CONVERSION CHAINS OPTIMIZATION}

\section{A. Hybrid excitation synchronous generator consideration}

To evaluate the conversion chain active masses of a full magnetic indirect drive (FMID), it is necessary to integrate a model of the active part masses of the generator. The generator studied in this article is a hybrid excitation synchronous generator developed by Jeumont Electric [11]-[12]. Considering the conversion chain presented in Table 4, the input torque of the generator $T_{S G}$ depend on the gear ratio of the FMID $G_{F M I D-i s}$ with $i$ stages ( $i=1$ or 2 ) (18). To determine the mass of this generator, it is considered that the torque $T_{S G}$ of the generator is a function of the external diameter $D_{S G}$ and the length $L_{S G}$ of the generator with a constant tangential stress $\sigma_{t}=5.10^{4} \mathrm{~N} / \mathrm{m}^{2}(19)$. 


$$
\begin{gathered}
T_{S G}=\frac{T_{\text {rated }}}{G_{F M I D-i S}} \\
T_{S G}=\sigma_{t} \cdot 2 \pi \frac{D_{S G}{ }^{2}}{4} L_{S G}
\end{gathered}
$$

For an external diameter of the generator $D_{S G}$ equal to the external diameter of the magnetic gear, (19) permits to impose the length of the synchronous generator (because the torque of the generator is imposed by the relation (18)) as shown in (20). From a generator active length equal to $0.2 \mathrm{~m}$ (for high global gear ratio), the length of the generator is fixed equal to $0.2 \mathrm{~m}$ and the external diameter of the generator is determined from (19) as shown in (21).

$$
\begin{gathered}
\left\{\begin{array}{c}
D_{S G}=D_{G M} \\
L_{S G}=\frac{T_{S G}}{\sigma_{t} \cdot 2 \pi \frac{D_{S G}{ }^{2}}{4}}
\end{array}\right. \\
\left\{\begin{array}{c}
L_{S G}=0.2 \mathrm{~m} \\
D_{S G}=\sqrt{\frac{T_{S G}}{\sigma_{t} \cdot 2 \pi \frac{L_{S G}}{4}}}
\end{array}\right.
\end{gathered}
$$

It is then possible to compute the mass of the synchronous generator $M_{S G}$ with the relation (20) which depends directly on the gear ratio of the FMID $G_{F M I D-i S}$, where $\rho_{e q}$ corresponds to the equivalent density of the magnetic part materials of the generator $\left(\rho_{e q}=7500\right.$ $\mathrm{kg} / \mathrm{m}^{3}$ ) and $\xi$ corresponds to the filling factor of the synchronous generator developed by Jeumont Electric $(\xi$ $=0.45)$.

$$
M_{S G}\left(G_{F M I D-i S}\right)=\rho_{e q} \frac{\pi \cdot D_{S G}^{2}(1-\xi)}{4} L_{S G}
$$

\section{B. Optimization of a conversion chain with one or two magnetic gear stages}

Considering the fitted curve Pareto $(G)$ (15) which gives the evolution of the magnetic mass of the magnetic gear depending on the gear ratio, and considering (22) which give the mass of the synchronous generator, it is possible to define a function $M_{F M I D-1 S}\left(G_{F M I D-1 S}\right)$ (23) which gives the mass of the FMID conversion chain with one stage of magnetic gear. For a FMID with two stages, the mass of the active parts of the conversion chain $M_{F M I D-2 S}\left(G_{1}, G_{F M I D-2 S}\right)$ is given by (24) and the evolution of the mass $M_{F M I D-2 S}$ in function of $G_{1}$, the gear ratio of the first stage is given by Fig. 8 .

$$
\begin{aligned}
& M_{F M I D-1 S}\left(G_{F M I D-1 S}\right)= \\
& T_{\text {rated }} \cdot \text { Pareto }\left(G_{F M I D-1 S}\right)+M_{S G}\left(G_{F M I D-1 S}\right) \\
& M_{F M I D-2 S}\left(G_{1}, G_{F M I D-2 S}\right)=T_{\text {rated }} \cdot \text { Pareto }\left(G_{1}\right) \\
& +\frac{T_{\text {rated }}}{G_{1}} \text {.Pareto }\left(\frac{G_{F M I D-2 S}}{G_{1}}\right)+M_{S G}\left(G_{F M I D-2 S}\right)
\end{aligned}
$$

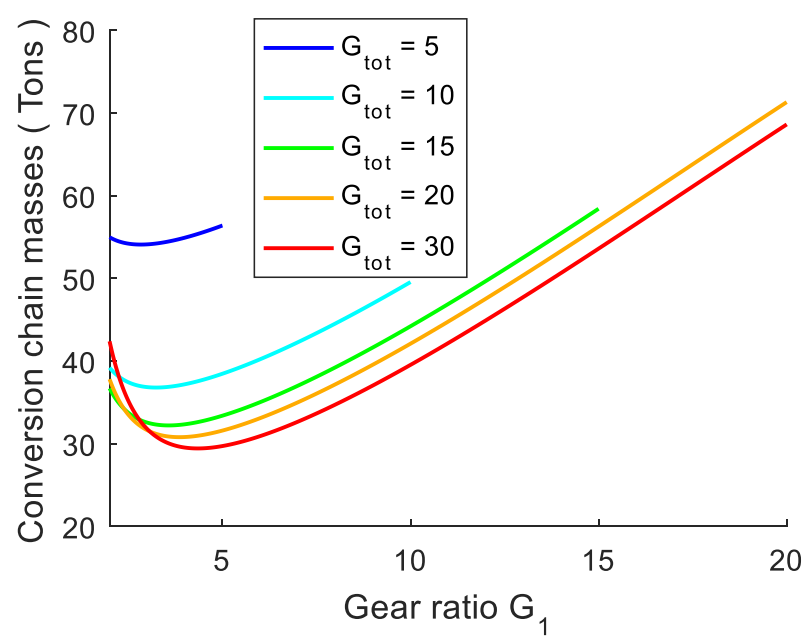

Fig. 8 Evolution of active mass of the FMID conversion chain with two magnetic gear stages versus the gear ratio $\left(\mathrm{G}_{1}\right)$ of the first stage for the wind turbine presented in Table 4 .

Fig. 8 shows that the optimum of the first stage gear ratio increases with the global gear ratio of a FMID with two magnetic gear stages $G_{F M I D-2 S}$. From the curve of Fig.8, it is possible to extract the optimums for different global gear ratio and compared the mass of the active parts of the two FMID conversion chain (with one or two magnetic gear stages) with the mass of a direct drive conversion chain with the same hybrid excitation synchronous generator developed by Jeumont Electric.

\section{Comparison of the three conversion chain}

Fig. 9 shows the evolution of the minimal mass of the active parts of a FMID with two magnetic gear stages (Fig.8). Table 5 lists, for the optimal solutions of the three conversion chains (single stage FMID, double stage FMID and direct drive), the repartition of the masses between magnetic gears and synchronous generator. It can be observed that for the single stage FMID, the mass of the magnetic gear corresponds to 55\% of the mass of the conversion chain and for the double stage FMID, the mass of the both magnetic gears correspond to $79 \%$ of the mass of the conversion chain. 


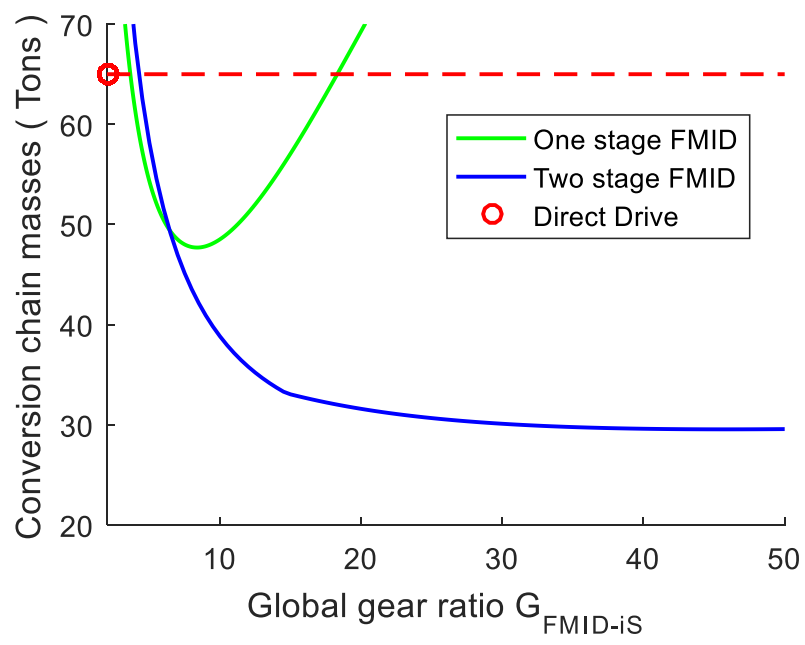

Fig. 9 Comparison between conversion chains composed of a single stage FMID, a two stages FMID and a direct drive with the same topology of hybrid excitation synchronous generator developed by Jeumont Electric for the wind turbine presented in Table 4.

TABLE 5: ACTIVE MASSES REPARTITION OF THE THREE STUDIED CONVERSION CHAINS (SINGLE STAGE FMID, DOUBLE STAGE FMID AND DIRECT DRIVE).

\begin{tabular}{|c|c|c|c|c|c|c|}
\hline & \multicolumn{2}{|c|}{$\begin{array}{c}\text { Single stage } \\
\text { FMID } \\
\text { masses }\end{array}$} & \multicolumn{2}{c|}{$\begin{array}{c}\text { Double stage } \\
\text { FMID masses }\end{array}$} & \multicolumn{2}{c|}{ Direct drive } \\
\cline { 2 - 7 } & $1 \mathrm{e}^{3} \mathrm{~kg}$ & $\%$ & $1 \mathrm{e}^{3} \mathrm{~kg}$ & $\%$ & $1 \mathrm{e}^{3} \mathrm{~kg}$ & $\%$ \\
\hline $\begin{array}{c}\text { First stage of } \\
\text { magnetic gear }\end{array}$ & 26.2 & 55 & 17.7 & 60 & - & - \\
\hline $\begin{array}{c}\text { Second stage of } \\
\text { magnetic gear }\end{array}$ & - & - & 5.7 & 19 & - & - \\
\hline $\begin{array}{c}\text { Synchronous } \\
\text { generator }\end{array}$ & 21.5 & 45 & 6.1 & 21 & 65 & 100 \\
\hline Total & $\mathbf{4 7 . 7}$ & $\mathbf{1 0 0}$ & $\mathbf{2 9 . 5}$ & $\mathbf{1 0 0}$ & $\mathbf{6 5}$ & $\mathbf{1 0 0}$ \\
\hline
\end{tabular}

Results of this FMID conversion chains optimization (for a $6 \mathrm{MW} 12.5 \mathrm{rpm}$ wind turbine) show that the optimal global gear ratio is equal to 8.5 for a single stage FMID and 46 for a two stages FMID. The active parts masses of the conversion chain are then equal to 47.7 Tons and 29.5 Tons for the single and double stage FMID respectively (visible Fig.9). They are equal to 65 Tons for the direct drive design with the same topology of hybrid excitation synchronous generator. For a global gear ratio $3.6<$ $G_{F M I D-1 S}<18.3$ for the single stage FMID and $4.2<$ $G_{F M I D-2 S}<50$ for the double stage FMID, the mass of the active parts of the conversion chain is lower than the mass of the active parts of the direct drive conversion chain.

These results - which show that the double stage FMID optimal masses is lower than the single stage FMID optimal masses which is also lower than the direct drive masses - have to be weighted because the optimization does not take into account the structural part which constitutes an important contribution of the conversion chain. Furthermore, adding magnetic gear stages to a direct drive will inevitably strongly increase the total mass of the structural parts (this is reinforced with the double stage FMID).

\section{CONCLUSION}

This article deals with the optimization of full magnetic indirect drive (FMID) with magnetic gears described with an analytical model. A bi-objective analytical optimization is performed with a PSO algorithm with minimization of the mass of the magnetic parts and maximization of gear ratio for a magnetic gear. This intermediate optimization was a step to optimize a $6 \mathrm{MW}$ FMID for offshore wind turbine with one or two magnetic gears stages necessary to compare the mass of the FMID configuration with the mass of a direct drive conversion chain with the same topology of hybrid excitation synchronous generator.

It can be concluded that:

1) The full magnetic indirect drive conversion chain designed with 1 or 2 magnetic gear stages has a lower mass than the direct drive design if only the active parts of the conversion chain are taken into account. Then, in this example, the optimal global gear ratio for the single stage FMID is 8.5 and 46 for the double stage FMID.

2) The conversion chain which offers the minimal masse of the active parts between the three studied configurations (single stage FMID, double stage FMID and direct drive) is the double stage FMID with an active part masses repartition between magnetic gears and generator composed of 23.4 Tons for the magnetic gear(s) and 6.1 Tons for the synchronous generator (which corresponds to $21 \%$ of the active part masses of the conversion chain).

To improve the design and the optimization of the conversion chains with magnetic gears in a wind turbine context, it is possible to develop an analytical mechanical model of a FMID structural parts to perform a mechatronic global optimization of single or double stages FMID. The result of this optimization will be different to the optimization described in this article because the structural part masses correspond to the major contribution of the conversion chain mass and may benefit the direct drive solution. 


\section{REFERENCES}

[1] R. Lacal Arántegui and J. Serrano Gonzáles, 2014 JRC wind status report: Technology, market and economic aspects of wind energy in Europe. 2015.

[2] J. Keller, Y. Guo, and L. Sethuraman, "Gearbox Reliability Collaborative Investigation of Gearbox Motion and HighSpeed-Shaft Loads," NREL, Tech. Rep. TP-5000-65321, 2016.

[3] W. Teng, X. Ding, X. Zhang, Y. Liu, and Z. Ma, "Multi-fault detection and failure analysis of wind turbine gearbox using complex wavelet transform," Renew. Energy, vol. 93, pp. 591-598, 2016.

[4] M. Desvaux, R. L. G. Latimier, B. Multon, H. Ben Ahmed, and S. Sire, "Design and optimization of magnetic gears with arrangement and mechanical constraints for wind turbine applications," in 2016 11th International Conference on Ecological Vehicles and Renewable Energies, EVER 2016, 2016.

[5] D. Matt, J. Jac, and N. Ziegler, "Design of a Mean Power Wind Conversion Chain with a Magnetic Speed Multiplier," in Chap. 10 of InTech book "Advances in Wind Power, 2012, pp. 247-266.

[6] T. B. Martin, "Magnetic transmission," Pat. US3378710, 1968.

[7] K. Atallah and D. Howe, "A novel high-performance magnetic gear," IEEE Trans. Magn., vol. 37, no. 4, pp. 28442846, 2001.

[8] K. Atallah, S. D. Calverley, and D. Howe, "Design, analysis and realisation of a high-performance magnetic gear," IEE Proc - Electr. Power Appl., vol. 151, no. 2, pp. 135-143, 2004.

[9] P. O. Rasmussen, T. O. Andersen, F. T. Jørgensen, and O. Nielsen, "Development of a high-performance magnetic gear," IEEE Trans. Ind. Appl., vol. 41, no. 3, pp. 764-770, 2005.

[10] N. W. Frank and H. A. Toliyat, "Gearing ratios of a magnetic gear for wind turbines," in 2009 IEEE International Electric Machines and Drives Conference, IEMDC '09, 2009.

[11] A. Ammar, F. Gillon, and P. Brochet, "The Double Excitation: A Solution to Improve Energetic Performances of High Power Synchronous Machines," J. Energy Power Eng., vol. 6, no. 5, pp. 719-724, 2012.

[12] A. Ammar, A. C. Berbecea, F. Gillon, and P. Brochet, "Influence of the ratio of hybridization on the performances of synchronous generator with Hybrid Excitation," Proc. 2012 20th Int. Conf. Electr. Mach. ICEM 2012, pp. 29212926, 2012.

[13] E. Gouda, S. Mezani, L. Baghli, and A. Rezzoug, "Comparative study between mechanical and magnetic planetary gears,” IEEE Trans. Magn., vol. 47, no. 2, pp. 439450, 2011.

[14] A. Penzkofer and K. Atallah, "Magnetic Gears for High Torque Applications," IEEE Trans. Magn., vol. 50, no. 11, 2014.

[15] L. Jing, L. Liu, M. Xiong, and D. Feng, "Parameters Analysis and Optimization Design for a Concentric Magnetic Gear Based on Sinusoidal Magnetizations," IEEE Trans. Appl. Supercond., vol. 24, no. 5, 2014.

[16] R. Mathis and Y. Rémond, "A unified theory of epicyclic gear trains," C. R. Acad. Sci. Paris, pp. 1115-1121, 1999.

[17] T. Lubin, S. Mezani, and A. Rezzoug, "Analytical computation of the magnetic field distribution in a magnetic gear," IEEE Trans. Magn., vol. 46, no. 7, pp. 2611-2621, 2010.

[18] M. Desvaux, B. Traullé, R. L. G. Latimier, S. Sire, B. Multon, and H. Ben Ahmed, "Computation Time Analysis of the Magnetic Gear Analytical Model," IEEE Trans. Magn. , Submitt., 2016.

[19] J. G. Van Bladel, "Electromagnetic Fields: Second Edition," Electromagn. Fields Second Ed., pp. 1-1147, 2006.

[20] F. S. J., "Partial Differential Equations for Scientists and Engineers." 1982.

[21] S. Niu, N. Chen, S. L. Ho, and W. N. Fu, "Design optimization of magnetic gears using mesh adjustable finiteelement algorithm for improved torque," IEEE Trans. Magn., vol. 48, no. 11, pp. 4156-4159, 2012.

[22] J. Aubry, H. Ben Ahmed, and B. Multon, "Sizing optimization methodology of a surface permanent magnet machine-converter system over a torque-speed operating profile: Application to a wave energy converter," IEEE Trans. Ind. Electron., vol. 59, no. 5, pp. 2116-2125, 2012.

[23] S. L. Ho and H. C. Wong, "A particle swarm optimization method with enhanced global search ability for design optimizations of electromagnetic devices," IEEE Trans. Magn., vol. 42, no. 4, pp. 1107-1110, 2006. 